Original Article

\title{
ANTIHYPERCHOLESTEROLEMIC AND ANTIATHEROGENIC POTENTIAL OF AQUEOUS EXTRACT OF ADANSONIA DIGITATA STEM BARK INDUCED BY HEATED PALM OIL SUPPLEMENTED WITH EGG YOLK IN RAT
}

\author{
CHRISTIAN BONABE ${ }^{*}$, FIDELE NTCHAPDA ${ }^{1}$, ALBERT DONATIEN ATSAMO ${ }^{2}$, SOUDY IMAR DJIBRINE ${ }^{3}$, ESTHER \\ NGO LEMBA TOM ${ }^{4}$, YANNICK BEKONO FOUDA ${ }^{2}$, DAVID MIAFFO ${ }^{5}$, THEOPHILE DIMO ${ }^{2}$
}

${ }^{1}$ Department of Biological Sciences, Faculty of Sciences, University of Ngaoundere, P. O. Box 454, Ngaoundere, Cameroon, ${ }^{2}$ Department of Animal Biology and Physiology, University of Yaoundé I, P. O. Box 812, Yaounde, Cameroon, ${ }^{3}$ Institut Universitaire des Sciences et

Techniques d'Abeche (IUSTA), P. O. Box 6077, N'Djamena, Tchad, 'Department of Biological Sciences, Higher Teachers' Training Colleges, University of Yaounde I, P. O. Box 47, Yaounde, Cameroon, ${ }^{5}$ Department of Life and Earth Science, Higher Teachers' Training College,

University of Maroua, P. O. Box 55 Maroua, Cameroon

Email: bonabe1985@yahoo.fr

Received: 16 Jan 2021, Revised and Accepted: 31 May 2021

ABSTRACT

Objective: Poor control of hypercholesterolemia which mediated by overproduction of reactive oxygen species and endothelial dysfunction leads to atherosclerosis. The present study aimed to investigate the antihypercholesterolemic and anti-atherogenic effects of Adansonia digitata (AD) in heated palm oil/cholesterol supplemented with egg yolk in rat.

Methods: Quantitative phytochemical screening of aqueous extract of A. digitata was carried out to identify the phytoconstituents. In vitro and in vivo antioxidant potential was evaluated. The antihypercholesterolemic and anti-atherosclerosis activity of $A$. digitata was evaluated by inducing hypercholesterolemia in rats with heated palm oil/cholesterol diet supplemented with egg yolk for $10 \mathrm{w}$. At the end of the induction period, animals were divided into 5 groups of 8 rats each after 6 w of induction: Group I (normocholesterolemic rat, NCR), Group II (hypercholesterolemia rat, HCR), Group III (Atorvastatin $2 \mathrm{mg} / \mathrm{kg}$ ), Groups IV (AD. $100 \mathrm{mg} / \mathrm{kg}$ ) and V (AD. $200 \mathrm{mg} / \mathrm{kg}$ ). Hemodynamic parameters, lipid profile, atherogenic indices and oxidative stress markers were evaluated.

Results: Adansonia digitata significantly reduced the systolic arterial blood pressure (SBP), diastolic arterial blood pressure (DBP), pulsatile pressure (PP) and heart rate compared to the hypercholesterolemic group. Plant extract reveal important flavonoids and phenolic contents and has significant in vivo antioxidant efficacy. The higher dose $(200 \mathrm{mg} / \mathrm{kg})$ of the extract significantly reduced in the level of total cholesterol by $27.29 \%$, triglycerides by $27.60 \%$ and the LDL-c by $36.04 \%$ meanwhile the HDL-c increased by $277.47 \%$ when compared to 5 HPOC treated group. Atorvastatin $(2 \mathrm{mg} / \mathrm{kg})$ administered in addition to 5 HPOC significantly improved in lipid profile as compared to untreated rats. Furthermore, the histopathological examination of aorta of 5HPOC-treated rats indicated that the aqueous extract of $A$. digitata significantly attenuated atherosclerosis lesions.

Conclusion: The aqueous extract of $A$. digitata possessed antihypercholesterolemic and anti-atherogenic effects via modulation overproduction of reactive oxygen species and endothelial dysfunction.

Keywords: Adansonia digitata, Lipid profile, Antioxidant potential, Atherogenic indices

(C) 2021 The Authors. Published by Innovare Academic Sciences Pvt Ltd. This is an open access article under the CC BY license (https://creativecommons.org/licenses/by/4.0/) DOI: https://dx.doi.org/10.22159/ijpps.2021v13i7.40785. Journal homepage: https://innovareacademics.in/journals/index.php/ijpps.

\section{INTRODUCTION}

Hypercholesterolemia is one of the leading causes of death in the developed countries. It is a chronic progressive disease which commonly affects arteries, resulting in reduced blood flow that eventually predisposes to various ailments such as coronary artery disease, myocardial infarction and cerebrovascular disease [1,2].

The relationship between hypercholesterolemia and cardiovascular mortality has been known for decades. Hypercholesterolemia which is a risk factor in the progression of atherosclerosis is characterized by an increase in the levels of low-density lipoprotein cholesterol (LDL-c), very low-density lipoprotein cholesterol (VLDL-c) and a decrease in high-density lipoprotein cholesterol (HDL-c) [3]. Moreover, several experimental studies have demonstrated that, in addition to its wellknown proatherogenic effect in the vasculature, hypercholesterolemia may directly affect the heart causing contractile dysfunction [4].

Accumulating evidence has shown that reactive oxygen species (ROS) generated during hypercholesterolemia are involved in key processes in the development and progression of atherosclerosis, including endothelial dysfunction and oxidative modification of low-density lipoprotein [5]. In general, lipid metabolism imbalance results from the interaction between genetics and environmental factors, such as eating habits, especially high lipid consumption. Therefore, diet lipid content has been investigated as a key factor in preventing cardiovascular disease, including hypercholesterolemia. Experimental studies with high-fat diets have used very high contents of dietary fat, in short-period protocols, without finding serum lipid impairment. On the other hand, Lipid structure, composition, configuration, in addition to excessive fat and cholesterol consumption are also believed to affect the lipid profile in the plasma.

Several studies were investigated, inducing hypercholesterolemia in rats is often through a high fat, high cholesterol diet, with the fat source varying from lard, coconut, soybean or palm oil only or in associated [6]. Therefore, it was of great interest to understand the antioxidant activity of $A$. digitata aqueous extract on hypercholesterolemia. The present study was designed to evaluate the antihypercholesterolemic and anti-atherosclerotic effects of the aqueous extract stem bark of $A$. digitata in rats.

\section{MATERIALS AND METHODS}

\section{Chemicals and reagents}

Cholesterol, highly Purified obtained from Calbiochem 1-800-2220342 (U. S. and Canada); 2,2-diphenyl-1-picrylhydrazyl radicalscavenging (DPPH); Folin-Ciocalteu reagent (Sigma chemical Co., St. 
Louis, Mo); 2,4,6-tripyridyl-striazine TPTZ) and Ferric ion Reducing Antioxydant Parameter (FRAP) obtained from Sigma (U. S.). All other chemicals and reagents used, including (catechin, aluminum chloride, potassium acetate, acetate buffer, chloroform, glacial acetic acid, urethane) in the present study were obtained commercially and were of analytical grade.

\section{Animals}

The antihypercholesterolemia activity was carried out on fifty healthy male albino Wistar rats aged 6-8 $\mathrm{w}$ and weighting 180-200 g prior to the experiment. Animals were housed in standard environmental conditions under a 12/12 h light/dark natural cycle in the animal house of the Laboratory of Animal Physiology of the University of Yaoundé I. Animals had free access to standard diet and tap water ad libitum. All animals treatment procedures used in the present study were approved by the Cameroon National Ethical Committee (Ref. ${ }^{\circ}{ }^{\circ}$ FWIRB 00001954).

\section{Source and preparation of diets}

Commercially purchased palm oil local used was five-times-heated, according to the modified method as described by Owu et al. [7-9]. Briefly, $2.5 \mathrm{~L}$ of palm oil was heated in a metal wok at $150{ }^{\circ} \mathrm{C}$ for 10 min. To prepare five-times-heated oil, the whole heating process was repeated four more times with a fresh batch and five hours cooling interval. No fresh oil was added between batches to replace oil absorbed by the heating. The test diets were formulated by mixing $15 \%(\mathrm{w} / \mathrm{w})$ of five-heated palm oil with ground $0.5 \%$ cholesterol diet supplemented with egg yolk.

\section{Preparation of the aqueous extract}

Samples of $A$. digitata were collected in the town of Maroua, Diamaré, Far North Region (Cameroon), in November 2017. A sample was idefieid, authenticated, and stored (Cameroon National Herbarium SpecimenNo42417/HNC, Yaoundé). The stem bark peels were air-dried at room temperature to avoid possible degradation or denaturation of their putative compounds. The airdried stem bark of $A$. digitata was blended to powder using an electric blender and stored in a glass container. About $100 \mathrm{~g}$ of the powder stem materials were extracted with $1000 \mathrm{ml}$ of distilled water for $24 \mathrm{~h}$. The macerate obtained was filtered using a Wattman No. 3 paper then, the resultant extract was dried in the oven at $45^{\circ} \mathrm{C}$. A solid mass of the aqueous stem bark extract was obtained and stored at $4{ }^{\circ} \mathrm{C}$ until use.

\section{Quantitative estimation of phytoconstituents}

The quantitative phytochemical screening of aqueous extract of stem bark of $A$. digitata was carried out to determine total phenolic and total flavonoids content using standard test.

\section{Determination of polyphenolic concentration}

The polyphenolic contents in the extract were measured using the Folin-Ciocalteu reagent (Sigma chemical Co., St. Louis, Mo), according to the method of Gabriel et al. [10]. Plant extract (60 $\mu$ ) was mixed with $2 \mathrm{ml}$ of Folin-Ciocalteu reagent diluted 10 times for the determination of free polyphenolic content. The extract concentrations were from 0.05 to $4 \mathrm{mg} / \mathrm{ml}$ (seven different concentrations). The absorbance was read at $750 \mathrm{~nm}$ after $30 \mathrm{~min}$ using a spectrophotometer (UV-Shimadzu). Catechin (Sigma) was used as standard and each concentration was replicated three times. The catechin concentrations were from 10 to $200 \mu \mathrm{g} / \mathrm{ml}$.

\section{Total flavonoids content}

The aluminum chloride colorimetric method was used to determine the flavonoid content of plant extracts. $0.5 \mathrm{mg} / \mathrm{ml}$ of extract solution was added into $1.5 \mathrm{ml}$ of methanol. $0.1 \mathrm{ml}$ of $10 \%$ aluminum chloride was added followed by incubation for $5 \mathrm{~min}$ after which 0.1 $\mathrm{ml}$ potassium acetate $(1 \mathrm{M})$. Finally, $2.8 \mathrm{ml}$ distilled water was added and shaked and kept at room temperature for $30 \mathrm{~min}$. Absorbance of the sample was noted at $420 \mathrm{~nm}$ with UV spectrophotometer. Quercetin was used as the standard for the calibration curve. Flavonoid contents were expressed as $\mathrm{mg} / \mathrm{g}$ quercetin equivalent dry weight. A yellow color indicated the presence of flavonoids.
From the standard graph, the amount of total flavonoids content in the sample as per absorbance values was calculated and expressed as quercetin equivalents $(\mathrm{mg} / \mathrm{g})$.

\section{In vitro antioxidant activity}

A. digitata antioxidant activity was assessed using different assays in vitro: 2,2-diphenyl-1-picrylhydrazyl radical-scavenging (DPPH) and Ferric ion Reducing Antioxydant Parameter (FRAP). Each test was done with three replicates.

\section{DPPH radical scavenging activity}

The hydrogen-donating ability of each extract was examined according to the method previously described by Bender et al. [11] in the presence of a DPPH stable radical. Gallic acid at various concentrations $(5-200 \mu \mathrm{g} / \mathrm{ml})$ was used as standard. The antioxidant activity was calculated as \% inhibition using the formula:

$$
\% \text { inhibition }=\frac{(\text { Ablank- Asample })}{\text { Ablank }} \times 100
$$

A blank = absorbance of the control

A sample $=$ absorbance in the presence of the extract.

The $\mathrm{EC}_{50}$ value $(\mathrm{mg} / \mathrm{ml})$, the effective concentration at which the DPPH radicals were scavenged by $50 \%$ was calculated with the equation from the curve. Gallic acid was used as positive control.

\section{Antioxidant potential by ferric reducing antioxidant power (FRAP)}

Extract antioxidant activity was measured by FRAP assay as described previously by Apak et al. [12]. Briefly, ferric to ferrous ion reduction at low $\mathrm{pH}$ forms a colored ferrous-2,4,6-tri (2-pyridyl)-striazine complex. Two milliliter $(2.0 \mathrm{ml})$ of FRAP reagent, containing

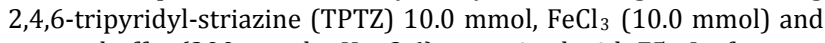
acetate buffer ( $300 \mathrm{mmol}$; $\mathrm{pH}=3.6$ ) was mixed with $75 \mu \mathrm{L}$ of extract or solvent (blank) to evaluate the free antioxidant capacity. The absorbance was read at $593 \mathrm{~nm}$ after $12 \mathrm{~min}$ of incubation. Catechin was used for calibration from 0.05 to $4.0 \mathrm{mg} / \mathrm{ml}$ as the extract.

\section{Estimation of iodine and peroxide values of palm oil}

The iodine/peroxide value of oil was determined according to the American Oil Chemists Society (AOCS) standard titration method [13].

\section{Study design}

The rats $(n=60)$ were allowed to acclimatize for $1 \mathrm{w}$ prior to treatment They were randomly divided into two groups. The first group made of 10 rats received basal diet (control) and the second group of 36 rats was received a basal diet fortified with $0.5 \%$ cholesterol, $15 \%$ heated palm oil (HPO) and egg yolk, for $6 \mathrm{w}$. After $6 \mathrm{w}$, control was maintained and the hypercholesterolemic group was further divided into the following four groups of 8 rats each: control negative receiving distilled water $(10$ $\mathrm{ml} / \mathrm{kg}$ by oral gavage) and 3 groups receiving by oral gavage aqueous extract of $A$. digitata (at the doses of 100 and $200 \mathrm{mg} / \mathrm{kg}$ ) or standard atorvastatin $(10 \mathrm{mg} / \mathrm{kg}, \mathrm{p} . \mathrm{o})$, respectively. Atorvastatin or aqueous extract in the vehicle was administered daily by oral gavage for the last 4 $\mathrm{w}$ of the study. The mean body weight and food intake were taken weekly during the study period.

\section{Hemodynamic parameters recording}

At the end of the investigation period, the blood pressure and heart rate of all rats were recorded. Briefly, each rat was anesthetized using an intraperitoneal injection of urethane $(1.5 \mathrm{~g} / \mathrm{kg})$. The trachea was exposed and cannulated to facilitate spontaneous breathing. The arterial blood pressure and heart rate were measured from the right carotid artery via an arterial cannula connected to a pressure transducer coupled with a hemodynamic recorder Biopac Student Lab. (MP35) and computer. Thirty minutes of equilibration period were observed before each measure.

\section{Blood and organs collection}

Immediately after hemodynamic parameters recording, blood samples were collected from the abdominal artery and centrifuged at $3000 \mathrm{rpm}$ for $15 \mathrm{~min}$. The plasma obtained was kept at $-20^{\circ} \mathrm{C}$ for 
biochemical analysis. Thereafter, the heart, kidney, liver, and thoracic aorta were collected, washed in saline, weighed, and kept for assessment of oxidative stress markers.

\section{Biochemical analysis}

The Mc Even solution was used to homogenize the heart and aorta while a Tris- $\mathrm{HCl}$ ( $50 \mathrm{mmol}$ ) buffer solution was used for the liver and kidney $(20 \%, \mathrm{w} / \mathrm{v})$. Each homogenate was centrifuged at $3000 \mathrm{rpm}$ for $25 \mathrm{~min}$ and stored at $-20{ }^{\circ} \mathrm{C}$. Tissue protein concentration was assayed according to Gornall et al. $[14,15]$ using the Biuret reagent (CALBIOCHEM, Germany). Malondialdehyde (MDA) was determined using the procedure of Wills et al. [16], whereas reduced glutathione (GSH) was determined using the method described by Ellman [17]. The serum concentrations of total cholesterol (TC), high-density lipoprotein cholesterol (HDL-c), low-density lipoprotein cholesterol (LDL-c), and triglycerides (TG) were determined using commercial diagnostic kits (CALBIOCHEM, Germany).

\section{Cardiovascular indices}

Atherogenic indices (AIP), cardiac risk ratio (CRR) and cardioprotective index (CPI) were calculated by using the values of lipid profile parameters in the following way Niroumand et al. [18]:

$$
\begin{gathered}
\mathrm{AIP}=\log \left(\frac{\text { Triglycerides }}{\mathrm{HDL}-\mathrm{c}}\right) \\
\mathrm{CRR}=\frac{\text { Total cholesterol }}{\mathrm{HDL}-\mathrm{c}} \\
\mathrm{CPI}=\frac{\mathrm{HDL}-\mathrm{c}}{\mathrm{LDL}-\mathrm{c}}
\end{gathered}
$$

\section{Histopathological analysis}

The aorta tissues samples were removed and preserved in $10 \%$ buffered formaldehyde and then processed, embedded in paraffin and sectioned ( $4 \mu \mathrm{m})$ as previously reported [19]. Cross abdominal aorta section was stained with hematoxylin-eosin and periodic acidSchiff stain. The morphological study was done by a pathologist in blinded randomized sections of the tissues, with light microscopy and using the most appropriate stain for each lesion.

\section{Statistical analysis}

The results were analyzed using GraphPad Prism software version 8.0.1 and expressed as mean \pm standard error of mean (SEM). The analysis of variance (ANOVA) was done for batch comparison. The Tukey post-test was applied to determine the difference between batches in case the ANOVA test was significant at least at $\mathrm{p}<0.05$.

\section{RESULTS}

\section{Total phenolic and flavonoid contents}

The phenolic and flavonoid contents of A. digitata were determined and values are shown in table 1 . The aqueous extract of $A$. digitata was found containing a significant amount of phenols and flavonoids as demonstrated by its total phenolic and flavonoid contents, with respective values of $666.08 \pm 14.95 \mathrm{mg} / \mathrm{g}$ cathechin equivalents $(\mathrm{EC} / \mathrm{g}$ ) and $116.54 \pm 3.33 \mathrm{mg} / \mathrm{g}$ quercetin equivalents (QUE/g).

\section{FRAP assay}

Table 1 shows the reductive capacities of the aqueous extract of $A$. digitata. The present of the reducers in plant extract causes the reduction of $\mathrm{F}^{3+} /$ ferricyanide complex to the ferreuse form. The FRAP assay was expressed as cathechin equivalent (EC) in $\mathrm{mg} / \mathrm{g}$ of samples used $\left(y=0.0632 x+0.2084 ; R^{2}=0.9986\right)$. The FRAP of aqueous extract of the A. digitata was $178.66 \pm 1.24$ catchechin equivalent $(\mathrm{mg} / \mathrm{g})$.

\section{Free radical scavenging assay (DPPH)}

The results expressed as a percentage of anti-radical activity (table 1) reveal that the aqueous extract of $A$. digitata tested exhibits inhibitory activity opposite the radical DPPH, with $60.37+0.52 \%$ compared to the standard for a maximum concentration of $100 \mu \mathrm{g} / \mathrm{ml}$. IC50 for DPPH radical-scavenging activity was $60.8 \mu \mathrm{g} / \mathrm{ml}$, the aqueous extract of $A$. digitata has moderate antioxidant power, it was relatively less potent than gallic acid whose value was in the order of $2.95 \mu \mathrm{g} / \mathrm{ml}$.

\section{Iodine and peroxide values}

The results investigated to determine the degree of unsaturation in palm oil show a highly significant increase in iodine and peroxide values of heated palm oil $\left(558.36 \pm 8.97 \mathrm{mg} / \mathrm{g}\right.$ and $\left.56.33 \pm 1.64 \mathrm{mEqO}_{2} / \mathrm{kg}\right)$, respectively compared with fresh oil $\left(3.34 \pm 0.12 \mathrm{mEqO}_{2} / \mathrm{kg}\right)$. The lower iodine value signifies low degree of unsaturation and the lesser the liability of the oil to become rancid by oxidation (table 1 ).

Table 1: Antioxidant activity, total phenols and total flavonoid of $A$. digitata extract

\begin{tabular}{lll}
\hline Samples & Parameters & Values \\
\hline A. & DPPH (\%) & $60.37 \pm 0.52$ \\
digitata & DPPH (IC $50 \mu \mathrm{g} / \mathrm{ml})$ & 60.8 \\
& FRAP $(\mathrm{mg}$ EC/g MS) & $178.66 \pm 1.24$ \\
& Total phenolic content (mg EC/g MS) & $666.08 \pm 14.95$ \\
& Total flavonoid content $(\mathrm{mg} \mathrm{EQ} / \mathrm{g} \mathrm{MS})$ & $116.54 \pm 3.33$ \\
Palm oil & Iodine index (mg/g) & $558.36 \pm 8.97$ \\
& Peroxide index $\left(\mathrm{mEqO}_{2} / \mathrm{kg}\right)$ & $56.33 \pm 1.64$ \\
\hline
\end{tabular}

Data are expressed as mean \pm SEM $(n=3)$ and analyzed by one-way ANOVA followed by the Tukey post-test.

\section{Bodyweight and food intake}

Comparison of the weight gain (fig. 1a) showed that at the end of the experimental period on the 42th day of the experiment induced, hypercholesterolemic rats $(\mathrm{HPOC})$ had higher $(\mathrm{P}<0.001)$ weight gain than the control group (fig. 1a). The difference between the control and the hypercholesterolemic groups started to become pronounced and significant from the two weeks until the end week of the experiment. After $42^{\text {th }}$ day of the experiment induced, an aqueous extract of $A$. digitata applied together with the hypercholesterolemic moderately reduced weight gain of the experimental animals significant. Additionally, there was no significant difference also, in the weekly intragastric application of the combination of the food intake in all study groups compared to the control (fig. 1b). (a)

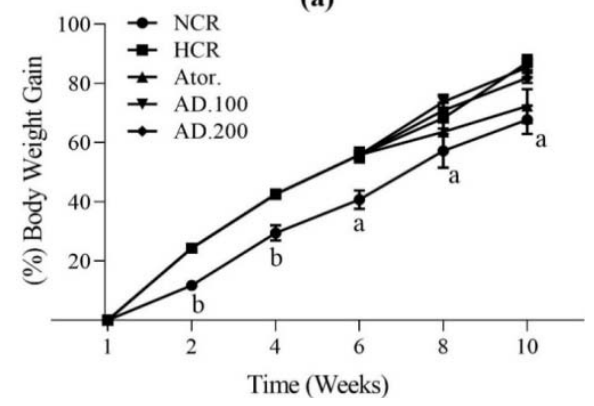

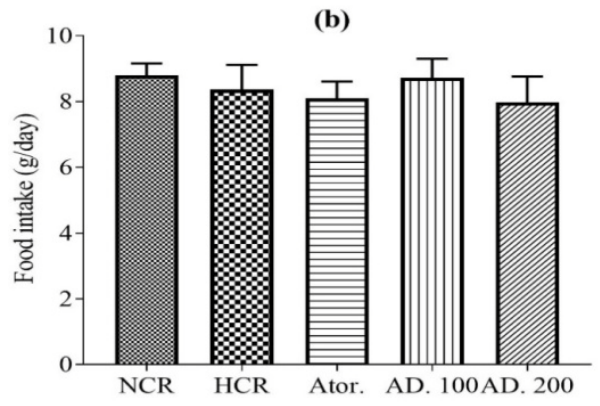

Fig. 1: Effect of aqueous extract of $A$. digitata or atorvastatin on body weight (a) and food intake in rat fed a HPOC diet supplemented with egg yolk. Data are expressed as mean $\pm \operatorname{SEM}(n=6)$ and analyzed by one-way ANOVA followed by the Tukey post-test. $\mathrm{cP}<0.05$, $b P<0.01$, aP<0.001 versus HCR group; NCR: Normocholesterolemic rat; HCR: Hypercholesterolemic rat; AD: Adansonia digitata; Ator: Atorvastatin 
Effect of aqueous extract of $A$. digitata on the blood pressure and heart rate

After $10 \mathrm{w}$ of the administration, the hypercholesterolemic group showed a significant increase of $22.68 \% ; 11.76 \%$ and $47.32 \%$ $(\mathrm{P}<0.001)$ in SBP; DBP and PP respectively compared to the control group. A. digitata at different doses caused a significant reduction in SBP, DBP ant PP relative to the hypercholesterolemic group. The dose of 100 and $200 \mathrm{mg} / \mathrm{kg}$ produced $(10.51 \%$ and $25.91 \%, \mathrm{P}<0.001)$ a reduction in SBP (2.85 \% and $21.88 \%, \mathrm{P}<0.001)$, DBP) and (23.59 \% and $32.81 \%$, $\mathrm{P}<0.001)$ and $\mathrm{PP}$, compared to the hypercholesterolemic group. Reduction in these values was significantly higher $(\mathrm{P}<0.001)$ than the $35.36 \%(\mathrm{P}<0.001)$ elicited by atorvastatin for PP. The heart rate $(\mathrm{HR})$ of rats that were orally administered the extract $(100$ and $200 \mathrm{mg} / \mathrm{kg}$ ) as well atorvastatin was lowered respectively by $7.44 \%, 12.31 \%$ and 4.27 $\%$, compared to the hypercholesterolemic group (table 2).

Table 2: Effects of the aqueous extract of $A$. digitata in blood pressure and heart rate

\begin{tabular}{|c|c|c|c|c|}
\hline Parameters & PAS (mm Hg) & PAD (mm Hg) & PP (mm Hg) & FC (bats/min) \\
\hline NCR & $101.67 \pm 2.75$ & $70.43 \pm 4.27$ & $31.23 \pm 3.36$ & $392.09 \pm 9.10$ \\
\hline HCR & $124.73 \pm 6.40^{a}$ & $78.72 \pm 5.19^{a}$ & $46.01 \pm 2.48^{a}$ & $316.17 \pm 2.54^{\mathrm{a}}$ \\
\hline Ator. & $92.30 \pm 2.95^{\alpha}$ & $62.56 \pm 4.43^{\alpha}$ & $29.74 \pm 1.80^{\alpha}$ & $329.63 \pm 5.75^{\alpha}$ \\
\hline AD. 100 & $111.63 \pm 2.84^{\alpha}$ & $76.47 \pm 3.20^{\alpha}$ & $35.16 \pm 2.07 \alpha$ & $339.69 \pm 22.53^{\alpha}$ \\
\hline AD. 200 & $92.41 \pm 7.41^{\alpha}$ & $61.49 \pm 5.74^{\alpha}$ & $30.92 \pm 2.47^{\alpha}$ & $355.10 \pm 12.57^{\alpha}$ \\
\hline
\end{tabular}

Data are expressed as mean \pm SEM $(n=6)$ and analyzed by one-way ANOVA followed by the Tukey post-test. aP<0.001:significantly different compared to HCR; $\alpha \mathrm{P}<0.001$ :significantly different compared to NHR. SBP: systolic arterial blood pressure; DBP: diastolic arterial blood pressure; PP: pulsatile pressure; HR: heart rate; HPOC: Heated palm oil/cholesterol; NCR: Normocholesterolemic rat; HCR: Hypercholesterolemic rat; AD: Adansonia digitata; Ator: Atorvastatin.

\section{Effect of aqueous extract of Adansonia digitata on lipid parameters}

As shown in table 3 , the daily ingestion of 5HPOC for 10 consecutive weeks significantly increased by $52.10 \%$ the level of total cholesterol (TC), by $57.36 \%$ the content of triglycerides (TG) and by $79.13 \%$ the LDL-c level while the HDL-c rate decreased by $73.23 \%$ respectively, compared to the normal control group. Treatment with the aqueous extract (100 and $200 \mathrm{mg} / \mathrm{kg}$ ) prevented the variation of serum TC, TG, LDL-c and HDL-c as compared to the 5HPOC treated group. The higher dose $(200 \mathrm{mg} / \mathrm{kg})$ of the extract significantly reduced in the level of total cholesterol by $27.29 \%$, triglycerides by $27.60 \%$ and the LDL-c by $36.04 \%$ meanwhile the HDL-c increased by $277.47 \%$ when compared to 5HPOC treated group. Atorvastatin $(2 \mathrm{mg} / \mathrm{kg}$ ) administered in addition to 5HPOC significantly improved in lipid profile as compared to untreated rats. AIP and CRR were significantly elevated in all groups receiving the HPOC supplemented with egg yolk compared to the control, while CPI was decreased. Atorvastatin or aqueous extract of plant protected all groups tested against an atherogenic index.

Table 3: Effects of aqueous extract of $\boldsymbol{A}$. digitata on serum compounds and atherogenic index

\begin{tabular}{|c|c|c|c|c|c|}
\hline Parameters & NCR & HCR & Ator. & AD. 100 & AD. 200 \\
\hline $\mathrm{TG}(\mathrm{mg} / \mathrm{dl})$ & $78.06 \pm 2.86$ & $122.86 \pm 5.05^{\mathrm{a}}$ & $73.88 \pm 2.79^{\alpha}$ & $103.54 \pm 3.84^{\alpha}$ & $88.94 \pm 3.43^{\alpha}$ \\
\hline $\mathrm{TC}(\mathrm{mg} / \mathrm{dl})$ & $87.86 \pm 4.47$ & $133.67 \pm 5.40^{a}$ & $100.90 \pm 5.05^{\alpha}$ & $95.04 \pm 9.48^{\alpha}$ & $97.19 \pm 8.07^{\alpha}$ \\
\hline LDL-C (mg/dl) & $41.23 \pm 0.97$ & $73.90 \pm 2.82^{\mathrm{b}}$ & $42.33 \pm 1.91^{\alpha}$ & $42.34 \pm 1.87 \beta$ & $47.21 \pm 1.48^{\delta}$ \\
\hline HDL-C (mg/dl) & $48.69 \pm 2.90$ & $14.66 \pm 2.98^{a}$ & $32.76 \pm 1.28^{\delta}$ & $26.70 \pm 1.97$ & $39.24 \pm 1.90^{\beta}$ \\
\hline CPI & $1.18 \pm 0.10$ & $0.20 \pm 0.06^{\mathrm{a}}$ & $0.77 \pm 0.11$ & $0.63 \pm 0.07$ & $0.83 \pm 0.08^{c}$ \\
\hline CRR & $1.80 \pm 0.30$ & $9.12 \pm 5.81^{\mathrm{a}}$ & $3.03 \pm 0.22^{\alpha}$ & $3.56 \pm 0.28^{\alpha}$ & $2.48 \pm 0.24^{\alpha}$ \\
\hline AIP & $0.20 \pm 0.08$ & $0.92 \pm 0.16^{\mathrm{a}}$ & $0.35 \pm 0.03$ & $0.59 \pm 0.11^{\mathrm{c}}$ & $0.36 \pm 0.06^{b}$ \\
\hline
\end{tabular}

Data are expressed as mean \pm SEM $(n=6)$ and analyzed by one-way ANOVA followed by the Tukey post-test. aP $<0.001$ :significantly different compared to HCR; $\alpha \mathrm{P}<0.001$ :significantly different compared to NHR. AIP: atherogenic indices; CRR: cardiac risk ratio; CPI: cardioprotective index (CPI) HPOC: Heated palm oil/cholesterol; NCR: Normocholesterolemic rat; HCR: Hypercholesterolemic rat; AD: Adansonia digitata; Ator: Atorvastatin.

\section{Effect of A. digitata on GSH levels}

Fig. 2a shows that GSH levels were significantly decreased in the heart by $52.45 \%(\mathrm{P}<0.001)$, aorta by $47.80 \%(\mathrm{P}<0.01)$, liver by $25.53 \% \quad(\mathrm{P}<0.001)$ and kidneys by $43.56 \% \quad(\mathrm{P}<0.001)$ of hypercholesterolemic treated rats compared to the normal control group. Nevertheless, the extract $(100$ and $200 \mathrm{mg} / \mathrm{kg}$ body weight/day) like captopril significantly prevented the decrease in GSH levels. A. digitata at the dose of $200 \mathrm{mg} / \mathrm{kg}$ exhibited a significant decrease of GSH in heart by $90.72 \%$, aorta by $63.69 \%$ $(\mathrm{P}<0.01)$, liver by $19.73 \%(\mathrm{P}<0.001)$ and kidney by $29.21 \%$ $(\mathrm{P}<0.01)$ as compared to the hypercholesterolemic group.

\section{Effect of $A$. digitata extract on nitrites content}

Fig. 2b represents the level of nitrites in aorta, heart, liver and kidney of different rat groups. Results of this study revealed hypercholesterolemic intake alone decreases the concentration of nitrites in the above tissues compared with normal control group. It decreased significantly in aorta by $48.41 \%(\mathrm{P}<0.001)$, heart by $45.16 \%(\mathrm{P}<0.001)$ and liver by $76.82 \%(\mathrm{P}<0.001)$ in the hypercholesterolemic group as compared to the normal group. The plant extract as well as atorvastatin prevented the deleterious effects of hypercholesterolemic in the tissues. The extract at the dose of $200 \mathrm{mg} / \mathrm{kg}$ significantly decreased the concentration of nitrite in aorta $107.47 \%(\mathrm{P}<0.001)$ and heart $124.83 \%(\mathrm{P}<0.001)$, compared to the hypercholesterolemic group.

\section{Effect of $A$. digitata on MDA levels}

MDA levels were significantly higher in heart by $54.20 \%$, aorta by $39.96 \%$, liver by $108.78 \%$ and kidney by $95.19 \%$ tissues of hypercholesterolemic treated rats as compared to the normal group. The administration of the plant extract prevented the rise in tissue MDA levels by $33.41 \%(\mathrm{p}<0.05)$ in the heart, $32.81 \%(\mathrm{p}<0.01)$ in aorta, $27.67 \%(\mathrm{p}<0.001)$ in liver and $37.08 \%$ in kidneys $(\mathrm{p}<0.001)$ at the dose of $200 \mathrm{mg} / \mathrm{kg}$ as compared to the hypercholesterolemic group. The same effect was observed with atorvastatin $(2 \mathrm{mg} / \mathrm{kg})$ and extract at the dose $100 \mathrm{mg} / \mathrm{kg}$ (fig. 2c).

\section{Histopathological of aorta}

The histology of aorta in heated palm oil/cholesterol supplemented with egg yolk-induced atherosclerosis is shown in fig. 3. In normal control, the thickness of tunica intima, media and adventitia appeared within normal limits. In the hypercholesterolemic group, 
the aorta section revealed initiation of atherosclerosis lesions with mild thickening of tunica intima which is start degeneration of endothelial cells responsible in formation of atheroma plaque. In atorvastatin and aqueous extract, the layers of artery appeared intact and few areas appeared disruption. Tunica adventitia appeared within normal limits and thickness. (a)

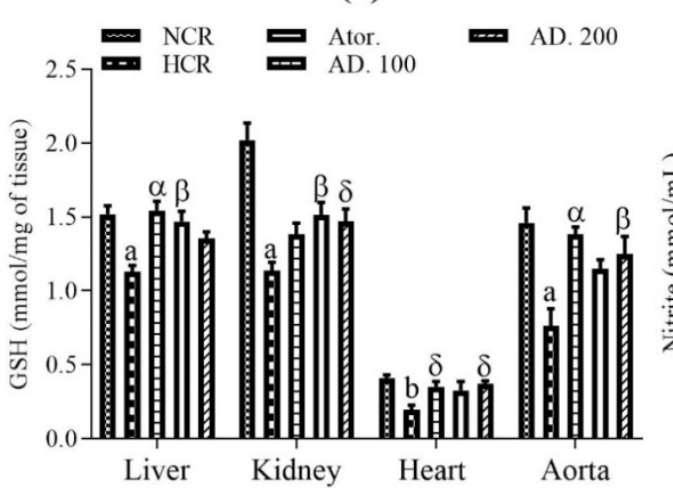

(b)

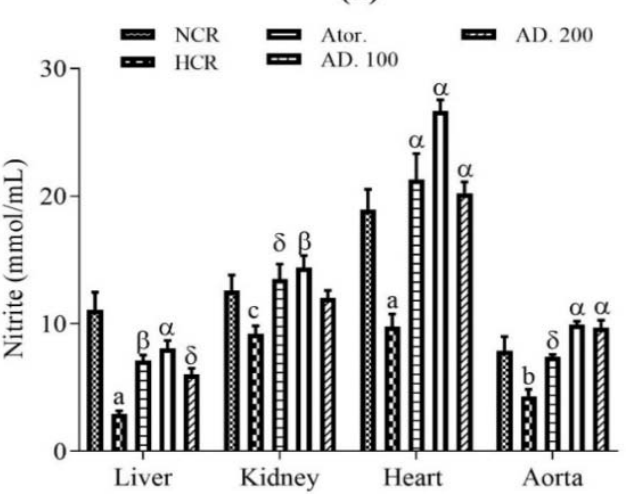

(c)

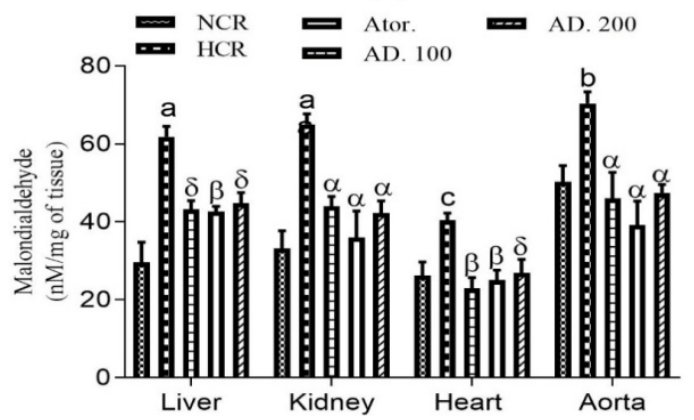

Fig. 2: Effect of A. digitata on GSH (a), nitrite (b) and MDA (c) levels of HPOC supplemented with egg yolk induced hypercholesterolemic rats. Data are expressed as mean $\pm \operatorname{ESM}(n=6)$ and analyzed by one-way ANOVA followed by the Tukey post-test. aP<0.001, bP<0.01, cP<0.05:significantly different compared to HCR. $\alpha P<0.001, \beta P<0.01, \delta P<0.05$ :significantly different compared to NHR. HPOC: heated palm oil/cholesterol; NCR: normocholesterolemic rat; HCR: hypercholesterolemic rat; AD: Adansonia digitata; Ator: Atorvastatin

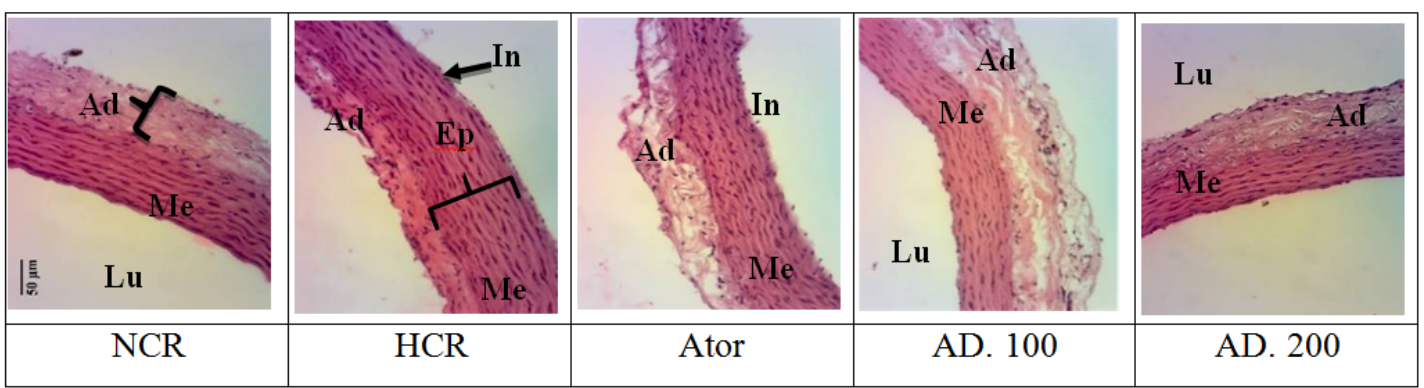

Fig. 3: Effect of atorvastatin and aqueous extract of $A$. digitata on HPOC supplemented with egg yolk induced alteration in aorta histology of rats. (Haematoxylin/Eosin staining; $x$ 100). Ad: adventice; In: intima; Me: media; Lu: lumen of aorta; Ep: media thickening; NCR: normocholesterolemic rat; HCR: hypercholesterolemic rat; AD: Adansonia digitata; Ator: Atorvastatin

\section{DISCUSSION}

It has been well established that nutrition plays an important role in the etiology of hypercholesterolemia and atherosclerosis. Also, several animal and human studies have confirmed the hypercholesterolemic properties of saturated fatty acids and cholesterol which include the elevated levels of TC, TG and LDL-c in serum are factors of risk for the development of atherosclerosis and other cardiovascular diseases (CVD) [20]. This study was carried out to ascertain the involvement of inflammation in hypercholesterolemia-related blood pressure elevation after consumption heated palm oil/cholesterol combined with egg yolk. We postulated that heating the palm oil repeatedly or high cholesterol would generate harmful ROS and hence induce inflammation and endothelial dysfunction. There was a significant increase in body weight at the end of the study for all the groups. This finding suggests that prolonged feeding with standard or HPOC fed supplemented with egg yolk did not affect the growth response. Non-significant reduction in the body weight was observed in the plant extract ameliorated throughout the experiment period when compared to the HPOC-fed Group.

In this study, chronic ingestion of cholesterol/heated palm oil combined with egg yolk for $10 \mathrm{w}$ caused a significant increase in BP as compared of the normal control. This significant increase in blood pressure was in agreement with a previous study Adam et al. [21] showing prolonged intake of repeatedly heated palm oil increased blood pressure. We believe that the feeding of repeatedly heated 
palm oil may contribute by over-production of reactive oxygen species-related blood pressure, as flected by the higher level of peroxide and iodine values in hypercholesterolemic group. Few studies have demonstrated the possible links between hypertension with the consumption of polar compounds in the cooking oil [22] and the increase in the levels of reactive oxygen species. Results disclose that the aqueous extract is efficient as an antihypertensive agent by significantly preventing the increase of blood pressure in diet-fed hypertensive rats. According to our results based on the antioxidative capacity of aqueous extract of $A$. digitata, it seems that $A$. digitata with its compounds is a strong inhibitor of oxidation stress, vascular irflammatio $\mathrm{n}$ and impairs the endothelial function. Oxidative stress, due to the over-production of ROS, can be diminished with aqueous extract of $A$. digitata by its antioxidant capacity, which can inactivate ROS and consequently counteract plasma ROS hence reducl in ammation of the blood vessel endothelium. Beside their antioxidant capacity, flavonoids improve lipid profile and have anti-inflammatory and antithrombotic effects as well. This antioxidative mechanism could contribute to the protective effect against cardi ovascular diseases or other chronic diseases connected with oxidative stress. The antihypertensive effects of this extract may also involve the beicial alteration in endothelium-derived factors. The presenfinding provides further support to the cardiovascular protective effect of aqueous extract of A. diditata.

Rats fed HPOC diet supplemented with egg yolk at the end of experimental period acts as extrinsic inducer and significantly increase the cholesterol, triglyceride, LDL levels and decrease HDL level. This is in accord with the previous finding reported by Varsha et al. [20] who showed that feeding rats with high cholesterol diet for $10 \mathrm{~d}$ induced hyperlipidemia. Increase in LDL might be oxidation of LDL into oxidated low-density lipoprotein (ox-LDL) indicates the first step of atherosclerosis in cardiovascular diseases, stimulating the immune and the inflammatory reactions that initiate the process of atherosclerotic plaque buildup [23]. Numerous experimental reports showed that high cholesterol diet has increase lipid status and increased lipid level act as an indicator of establishment of hypercholesterolemia in animal models [24]. HDL cholesterol is inversely connected with total cholesterol and several evidences are available regarding this fact. Therefore, HDL has a useful effect in reducing tissue cholesterol, and increasing ratio in serum is suggested while decreasing level that for LDL-cholesterol to reduce the risk of cardiovascular diseases [25]. In addition, HDL can reduce or neutralize the atherogenic effects of oxidized LDL in artery walls.

If it is taking into account the serum concentrations of total cholesterol, HDL, LDL and triglyceride in the hypercholesterolemic model. Our results indicated that the aqueous extracts of $A$. digitata possess a favorable effect in the management on rat's lipid profile with regard to the reduction of total cholesterol, LDL-cholesterol and triglycerides. The lipid-lowering potential of the extract may be attributed to the presence of phytochemical constituents such as flavonoids/polyphenols and its antioxidative capacity. Flavonoids are reported to lower LDL cholesterol and increase HDL-cholesterol concentrations in hypercholesterolemic animals [26].

It is known that reactive oxygen species (ROS) contribute to the pathogenesis of numerous cardiovascular diseases, including hypercholesterolemia. In the present work, antioxidant properties of the aqueous extract of $A$. digitata were determined by measuring GSH, MDA and NO activities in the tissues of rats hypercholesterolemic by HPOC supplemented with egg yolk. Treatment with aqueous extract of $A$. digitate, in our study results, improve a significant increasing free-radical-scavenging enzymes levels in tissues.

The antioxidant activity of the extract was evident in vivo by the protective effects of aqueous extract of $A$. digitata ability to prevent lipid peroxidation. That was shown with the low levels in MDA on different organs of antihypercholesterolemic rat treated with the plant extract. Inhibition of lipid peroxidation and production increase of GSH may confirm the implication of the antioxidant effect of the plant extract in the treatment of hypercholesterolemia. The significant increase in tissues GSH suggested that the activation of the GSH synthetic pathway does not occur as outcome of an increased production of free radicals. Also, Olukanni et al. [27] reported molecular evidence also suggest that the ability of some phenolic compounds to activate c-glutamylcysteine synthetase (a rate-limiting enzyme in GSH synthesis). In addition, the improved reduced glutathione activity may offer an effective defense system and prevent from the damage of free radicals. MDA is one of the endproducts of polyunsaturated fatty acid peroxidation and is a good indicator of the degree of lipid peroxidation [28, 29]. Our results indicated increase in MDA level in the homogenates tissues of hypercholesterolemic group, suggesting enhanced lipid peroxidation leading to tissue damage and failure of antioxidant defense mechanisms to prevent the formation of excessive free radicals. The reduced MDA content upon administration of the extract points out the favorable impact of this extract in breaking the chain reaction of lipid peroxidation engendered by chronic intake-fed. Inhibition of lipid peroxidation and production increase of GSH may confirm the implication of the antioxidant effect of the plant extract in the treatment of atherosclerosis. Similar results were obtained with Allanblacka floribunda ethanol extract when studying its antihypertensive activity related to its antioxidant potential [30]. The other major free-radical which contributes to oxidative/nitrative stress is NO. NO is responsible for the relaxation of vessels and plays an important role in matching tissue perfusion to demand [31] Considerable evidence indicates that overproduction of ROS under hypercholesterolemic conditions causes the inactivation of NO and the development of endothelial dysfunction, as well as the oxidative modification of LDL [32]. In addition, several studies demonstrated that NO is the major mediator of endothelium-dependent relaxation of rat aortae and that mechanism of vasorelaxation is impaired in many pathological diseases, including hypercholesterolemia and diabetes [33]. Our results also demonstrate aqueous extract of $A$. digitata significantly increase the NO level in the tissues. These findings suggest that chronic treatment with plant extract increases NO bioavailability and improves hypercholesterolemia-induced endothelial dysfunction.

\section{CONCLUSION}

The findings of the present study suggest that aqueous extract of A. digitata could be a potential source of antioxidants and could have greater importance as therapeutic agent in preventing or slowing down oxidative stress-related degenerative diseases. This antioxidant activity is due mostly to compounds with hydrogen donating ability which combined with its good chelating ability for ferrous ions contributing to protect vital organs. The antioxidant activity related to the beneficial effects of A. digitata administration on hypercholesterolemia is the reduction of oxidative stress in aortic tissues. Further, studies are required to again more insight in to the possible mechanism of action.

\section{ACKNOWLEDGEMENT}

The authors are thankful to the Laboratory of Medicinal Plants, Health and Galenic Formulation of the Faculty of Sciences, University of Ngaoundéré (Cameroon) for providing the facility to carryout the research.

\section{FUNDING}

\section{Nil}

\section{AUTHORS CONTRIBUTIONS}

$\mathrm{CB}$ and YBF proposed the plant material, harvested and prepared the crude extract. $\mathrm{CB}, \mathrm{YBF}$ and $\mathrm{AA}$ conducted the different tests in the laboratory and analyzed the data. $\mathrm{CB}, \mathrm{DM}$ and FN drafted the article. FN, TD and IDS corrected the final manuscript. All authors approved the final version of the manuscript.

\section{COMPETING INTERESTS}

The authors declare no conflict of interest.

\section{REFERENCES}

1. Child P, Kuksis A. Critical role of ring structure in the differential uptake of cholesterol and plant sterols by membrane preparations in vitro. J Lipid Res 1983;24:1196-209. 
2. Mazroatul C, Deni GD, Habibi NA, Saputri GF. Antihypercholesterolemia activity of ethanol extract peperomia pellucid. ALCHEMY J Penelitian Kimia 2016;12:88-94.

3. Pengnet S, Prommaouan S, Sumarithum P, Malakul W. Naringin reverses high-cholesterol diet-induced vascular dysfunction and oxidative stress in rats via regulating lox-1 and nadph oxidase subunit expression. Biomed Res Int 2019;2019:1-11.

4. Varga ZV, Kupai K, Szucs G, Gaspar R, Paloczi J, Farago N, et al. MicroRNA-25-dependent up-regulation of NADPH oxidase 4 (NOX4) mediates hypercholesterolemia-induced oxidative/ nitrative stress and subsequent dysfunction in the heart. J Mol Cell Cardiol 2013;62:111-21.

5. Jin P, Cong S. LOX-1 and atherosclerotic-related diseases. Clin Chim Acta 2019;491:24-9.

6. Otunola GA, Oloyede OB, Oladiji AT, Afolayan AA. Effects of diet-induced hypercholesterolemia on the lipid profile and some enzyme activities in female Wistar rats. Afr J Biochem Res 2010;4:149-54

7. Obembe AO, Owu DU, Okwari 00, Antai AB, Osim EE. Intestinal fluid and glucose transport in wistar rats following chronic consumption of fresh or oxidised palm oil diet. ISRN Gastroenterol 2011;2011:1-5.

8. Xian TK, Omar NA, Ying LW, Hamzah A, Raj S, Jaarin K, et al. Reheated palm oil consumption and risk of atherosclerosis: evidence at the ultrastructural level. Evid.-Based Complementary Altern Med 2012;2012:1-6.

9. Ani E, Ofem O, Owu D, Osim E. Distortions in sensitivity of carotid baroreceptor reflexes in rabbits following consumption of two forms of palm oil diets. Br J Med Med Res 2015;8:245-55.

10. Agbor AG, Vinson JA, Donnelly PE. Folin-ciocalteau reagent for polyphenolic assay. Int J Food Sci Nutr 2014;3:147-56.

11. Bender C. Stevia rebaudiana's antioxidant properties. In: Merillon JM, Ramawat KG. editors. Sweeteners. Cham: Springer International Publishing; 2018. p. 349-75.

12. Apak R, Guclu K, Ozyurek M, Bektasoglu B, Bener M. Cupric ion reducing antioxidant capacity assay for antioxidants in human serum and for hydroxyl radical scavengers. In: Armstrong D. editor. Advanced protocols in oxidative stress II. Totowa, NJ: Humana Press; 2010. p. 215-39.

13. Liu QX, Zhou YR, Wang M, Zhang Q, Ji T, Chen TY, Yu DC Adsorption of methylene blue from aqueous solution onto viscose-based activated carbon fiber felts: Kinetics and equilibrium studies. Adsorpt Sci Technol 2019;37:312-32.

14. Gornall AG, Bardawill CJ, David MM. Determination of serum proteins by means of the biuret reaction. J Biol Chem 1949;177:751-66.

15. Manzoor F, Nisa MU, Hussain HA, Ahmad N, Umbreen H. Effect of different levels of hydrolysable tannin intake on the reproductive hormones and serum biochemical indices in healthy female rats. Sci Rep 2020;10:20600.

16. Wills E. Mechanisms of lipid peroxide formation in animal tissues. Biochem J 1966;99:667-76.

17. Ellman GL. Tissue sulfhydryl groups. Arch Biochem Biophys 1959;82:70-7.

18. Niroumand S, Khajedaluee M, Khadem Rezaiyan M, Abrishami M, Juya M, Khodaee G, et al. Atherogenic index of plasma (AIP): a marker of cardiovascular disease. Med J Islam Repub Iran 2015;29:240.

19. Rodriguez Gomez I, Banegas I, Wangensteen R, Quesada A Jimenez R, Gomez Morales M, et al. Influence of thyroid state on cardiac and renal capillary density and glomerular morphology in rats. J Endocrinol 2013;216:43-51.

20. Dhulasavant V, Shinde S, Pawar M, Naikwade NS Antihyperlipidemic activity of cinnamomum tamala nees on high cholesterol diet-induced hyperlipidemia. Int J PharmTech Res 2010;2:5.

21. Adam SK, Das S, Jaarin K. A detailed microscopic study of the changes in the aorta of an experimental model of postmenopausal rats fed with repeatedly heated palm oil: repeatedly heated palm oil in ovariectomized rats. Int J Clin Exp Pathol 2009;90:321-7.

22. Soriguer F, Rojo Martinez G, Dobarganes MC, Garcia Almeida JM, Esteva I, Beltran M, et al. Hypertension is related to the degradation of dietary frying oils. Am J Clin Nutr 2003;78:1092-7.

23. Orsolic N, Landeka Jurcevic I, Dikic D, Rogic D, Odeh D, Balta V, et al. Effect of propolis on diet-induced hyperlipidemia and atherogenic indices in mice. Antioxidants 2019;8:156.

24. Devi S, Singh R. Antioxidant and anti-hypercholesterolemic potential of vitis vinifera leaves. Pharmacogn J 2017;9:807-14.

25. Nofer JR, Kehrel B, Fobker M, Levkau B, Assmann G, Eckardstein A von. HDL and arteriosclerosis: beyond reverse cholesterol transport. Atherosclerosis 2002;161:1-16.

26. Fidèle N, Joseph B, Emmanuel T, Theophile D. Hypolipidemic antioxidant and anti-atherosclerogenic effect of aqueous extract leaves of Cassia. occidentalis Linn (Caesalpiniaceae) in diet-induced hypercholesterolemic rats. BMC Complement Altern Med 2017;17:76

27. Adeyemi OS, Orekoya BT. Lipid profile and oxidative stress markers in wistar rats following oral and repeated exposure to fijk herbal mixture. J Toxicol 2014;2014:1-7.

28. Choudhary A, Mittal AK, Radhika M, Tripathy D, Chatterjee A, Banerjee UC, et al. Two new stereoisomeric antioxidant triterpenes from Potentilla fulgens. Fitoterapia 2013;91:290-7.

29. Dzeufiet PDD, Mogueo A, Bilanda DC, Aboubakar BFO, Tedong $\mathrm{L}$, Dimo $\mathrm{T}$, et al. Antihypertensive potential of the aqueous extract which combine leaf of Persea americana mill. (Lauraceae), stems and leaf of Cymbopogon citratus (D. C) Stapf. (Poaceae), fruits of Citrus medical L. (Rutaceae) as well as honey in ethanol and sucrose experimental model. BMC Complement Altern Med 2014;14:507.

30. Bilanda DC, Woguia AL, Djomeni Dzeufiet D, Kamtchouing P, Dimo T. Antioxidant activity of allanblackia floribunda trunk bark ethanol extract on alcoholinduced hypertensive rats. Trends Phytochem Res 2019;3:109-16.

31. Favero G, Paganelli C, Buffoli B, Rodella LF, Rezzani R. Endothelium and its alterations in cardiovascular diseases: life style intervention. Biomed Res Int 2014;2014:1-28.

32. Balarini CM, Leal MA, Gomes IBS, Pereira TMC, Gava AL, Meyrelles SS, et al. Sildenafil restores endothelial function in the apolipoprotein E knockout mouse. J Transl Med 2013;11:3.

33. Lu CW, Lin Y, Lei YP, Wang L, He ZM, Xiong Y. Pyrrolidine dithiocarbamate ameliorates endothelial dysfunction in thoracic aorta of diabetic rats by preserving vascular DDAH activity. PLoS One 2017;12:e0179908. 